\title{
PREDICTION OF DEPRESSION BY COGNITIVE FUNCTION ABOVE CORE AFFECT
}

\author{
Edmunds Vanags, Malgožata Raščevska \\ University of Latvia, Latvia
}

\begin{abstract}
The association between depression and cognitive function has been observed in a large number of studies, but there are no clear and robust mechanisms for this association. The aim of this study was to investigate how cognitive functions (working memory inhibition, executive functions cognitive control and psychomotor speed) in one model predict depression above current core affect in a sample of healthy individuals. The study involved 275 adults aged between 20 and 59 years (male 32.7\%) and used the depression scale from DASS-42 questionnaire, the Swedish Core affect scale, and the cognitive function task battery. The results of hierarchical regression analysis suggest that the depression is more significantly explained after controlling core affect by the working memory storage, inhibition, and executive function cognitive control processes, when performing several tasks with different valence words. This suggests that even in healthy individuals, there may be a significant association between depressive symptoms and cognitive function after controlling current core affect state which may fluctuate and not be reflected in the retrospective assessment.
\end{abstract}

Keywords: core affect, depression, executive functions, working memory.

\section{Introduction}

Depression is one of the most common types of mental disorders (WHO, 2021); however, research into the disorder is problematic (Fried, 2015). Though significant deficits follow in depression episode are observed in at least 55 cognitive variables, for example in processing speed, visual selective attention, working memory, verbal learning and executive functions domains (Semkovska et al., 2019), there is not clear whether such deficits exist before disorder onset and what are the mechanisms of such connections (Ji et al., 2020; Scult et al., 2017; Zuckerman et al., 2018). The most common studies have shown that depressive symptoms are usually significantly associated with executive functions and working memory deficits in range $d=-0.22$ to -0.54 (Rock et al., 2014) and even in healthy 
controls $d=-0.15$ (Knight et al., 2020). However, systematic reviews and meta-analyses suggest that these observations are heterogeneous and not consistent in all cases (Eysenck \& Fajkowska, 2018; Nikolin et al., 2021).

There are studies that induce mood changes (Chepenik et al., 2007) and investigate their relationship to cognitive performance, or the impact of various demographic variables on this relationship (Bora et al., 2013), but no studies have been found to measure retrospectively assessed symptoms of depression and their relation to cognitive processes, while controlling the current mood. Depressive disorders mostly are conceptualized as mood disorders and are assessed (Schraedley et al., 2002) usually asking respondents to rate their experience in last 2 weeks. However, the performance of cognitive tasks can also be influenced by the current mental state. The current mood is an assessment of the affective state experienced and, thus, reflects a significant portion of the entire affective repertoire and may contain significant portions of affective features, including signs of disorder. Thus is vital to control in relationships between depression and cognitive functions the current affect state. Core affect is seen as a broader, more general form of affect (Ekkekakis \& Petruzzello, 2002) and characterize the current mood (Västfjäll et al., 2002). Therefore, to determine which cognitive functions best predict depression it is necessary to first control the current affect in the regression model.

Such research is lacking and the role of cognitive function in depression controlling ongoing affect is not clear. In addition, studies suggest that fluctuations in daily positive and negative affect states are significant in depressive disorders (Schoevers et al., 2020), suggesting that a retrospective assessment of mood may include only some of the important information.

In previous studies, depressive disorders have been associated with low valence and low activation of the core affect (Clark \& Watson, 1991; Conway et al., 2017). The core affect is conceptualized as a neurophysiological state that is closely related to the current mood (Frijda, 1994), which can be expressed through two dimensions-valence and activation (Russell, 2003). Valence and activation are typically characterized by two dimensions and can be felt simultaneously because they are statistically independent, i. e., activation is not simply a degree of valence intensity (Cummins, 2014). In two-dimensional models, core affects are organized in a circular or circumplex structure (Russell, 2003). In this structure, the two main affect dimensions or axes reflect the degrees of pleasantness-unpleasantness and arousal or activation.

In addition, it can be observed that almost all studies use the same depression measuring instruments, which are known to measure quite different depressive syndromes or symptom profiles and their overlap is very weak (Fried, 2015, 2019). The most common systematic reviews and 
meta-analyzes analyzing the relationship between depression and cognitive function use the Hamilton Rating Scale for Depression, the MontgomeryÅsberg Depression Rating Scale, the Beck Depression Inventory-II, the Hamilton Depression Scale-17 (HAMD-17), which have quite different items, which measures different symptoms and their relationship to cognitive function is also quite suboptimal (Fried, 2017; Zuckerman et al., 2018).

One explanatory model of depression is the tripartite model of anxiety and depression, consisting of physiological hyperarousal, high negative affect, and low positive affect, which can conditionally distinguish between trajectories of depression and anxiety disorders.

In this study, measurements were based on a Depression Anxiety Stress Scales (DASS-42) (Lovibond \& Lovibond, 1995) instrument based on a tripartite anxiety and depression model (Clark \& Watson, 1991), and this scale was designed to better differentiate between the two disorders. According to the authors' description, the depression scale was based on the thoughts of clinical experts and research on other measures of depression. The authors of the DASS scale suggested that the structure of the seven symptoms in their instrument is well represented in other instruments of depression.

For measuring the cognitive functions, in this study we used several well-known neuropsychological cognitive tasks. It is known that psychomotor function is negatively correlated with depression (Huang, 2010; Liberg et al., 2013), as well verbal short- and long-term memory abilities and performance may be negatively associated with depressive disorders (Halvorsen et al., 2011). Executive functions, cognitive control in cognitive neuroscience is associated with control, executive, inhibitory dysfunction (DeLaRosa et al., 2020) which have been linked also to depression (Erickson et al., 2005). Recent theories offer the classical working memory model to be seen as an input-gate system (Gajewski et al., 2018; Kessler \& Oberauer, 2015) that continues to retain current information and provides its temporary stability. Thus working memory inhibition, updating and storage functions are related with depression disorders (Zhang et al., 2018).

The aim of study to explore how depression after controlling the dimensions of core affect is related to cognitive functions.

\section{Method}

\section{Participants}

The study involved 275 adults aged between 20 and 59 years $(M=37.47, S D=11.13$; male $32.7 \%)$ and whose average number of tears spent in education was $M=14.62, S D=3.66$. The participants in the study were recruited through a professional selection company, which sent 
out invitations to complete the demographic questionnaire electronically using age sampling criteria. Participants consisted of individuals from the convenience sample, and possible membership in the clinical group, occupation was not controlled. Participants were informed about the main goal of the study - the study of mood signs, cognitive skills. Participants were informed that participation in the study was voluntary and that they could terminate their participation at any time. Participants were invited to complete several tasks and questionnaires on the computer in person at certain times. Initially, participants completed core affect survey, then cognitive tests, finally a depression, anxiety, stress survey.

\section{Instruments}

1. The Latvian version of the Depression Anxiety Stress Scales (DASS-42) (Lovibond \& Lovibond, 1995; Vanags \& Raščevska, 2017) was used to assess the symptoms of depression. The Depression Anxiety Stress Scale was developed based on a tripartite model that allows the assessment of anxiety, depression, and stress symptoms (Clark \& Watson, 1991). In this model, the negative affect dimension can be seen as a basic component linking the dimensions of stress, anxiety, and depression. The original scale consists of 42 items arranged in three scales for measuring the symptoms of depression, anxiety, and stress. Only depression scale items were used in this study. The depression scale consists of 14 items that form seven subscale indicators of symptoms: dysphoria (feelings of sadness), hopelessness (difficulties in thinking about the future), devaluation of life (loss of meaning of life and feelings of the worthlessness of life), lack of interest (difficulties in become involved or losing interest in hobbies), anhedonia (difficulties in experiencing positive feelings and enjoyment), self-deprecation (feelings of self-worthlessness), and inertia (slowness and lacking in initiative).

For each symptom, two statements correspond and the average mean of them is calculated. For example, one of the anhedonia subscale items is "I couldn't seem to get any enjoyment out of the things I did" and one of the devaluations of life items is "I felt that life wasn't worthwhile". Each subjective assessment of a symptom and how often an individual observes them is rated on a scale of $0-3$. The depression scale summary and seven symptom subscale indicators were used for data analysis. The factorial and validity criteria of the Latvian version of the survey have been tested before and corresponded well to the adopted psychometric standards (Vanags \& Raščevska, 2017).

2. An adapted version of the Swedish core affect scale (SCAS) (Västfjäll et al., 2002) was used to measure the core affect, consisting of 12 items and four scales: valence, activation, pleasant activation/unpleasant 
deactivation, and unpleasant activation/pleasant deactivation. For example, Item 2 is a scale with "Drowsiness" at one end and "Alertness" at the other. The core affect is conceptualized as a neurophysiological state that is closely related to the current mood, which can be expressed through two dimensions-valence and activation. Valence and activation are typically characterized by two dimensions and can be felt simultaneously because they are statistically independent, i. e., activation is not simply a degree of valence intensity. In two-dimensional models, core affects are organized in a circular or circumplex structure. In this structure, the two main affect dimensions or axes reflect the degrees of pleasantness-unpleasantness and arousal or activation. Only valence and activation subscales were used in this study due to their better psychometric properties. Each item was assessed on a scale from 0 to 8 . The respondent chose how his or her current feelings fit into the particular dimension. The overall psychometric criteria are described in the original study (Västfjäll et al., 2002) and are appropriate.

3. For the purposes of this study, a battery of computerised cognitive tasks based on known test paradigms was developed. Based on the results of systematic analyzes (f. e. (Semkovska et al., 2019), it was intended to create such cognitive tasks that would include the same content elements verbal stimuli, and would be related to executive functions, working memory functions and verbal short-term and long-term memory functions. Although depressive disorders are related to many cognitive processes, executive functions, verbal memory and working memory are the most common. In this study, these functions were chosen to more likely to study the relationships controlling the core affect. The reliability and validity of the tasks were tested in pilot studies and the reliability of the repeated measurements (for the finger tapping test) as well as the convergent validity met the generally accepted psychometric criteria. Results of convergent validity is discussed in results section.

a) Finger tapping test (Reitan, 1696), which is one of the most common tests to assess motor, psychomotor function. In this study, task indicators are conceptualized as psychomotor speed. This task was chosen to control motor movements, motor speed, which is a variable present in computerized tasks where hands must be actively used.

b) Visual verbal learning and recognition test (Strauss et al., 2006) which is used to measure verbal short- and long-term memory abilities. The task displays 15 pre-selected different words on the computer screen, of which 5 are negative (eg killer), 5 positive (eg rest) and 5 neutral (eg table) words. After the words are displayed, they are displayed again, in a mixed order, with the other or false 15 words (negative, neutral and positive). The participant must press 
the key each time the previously memorized words appear. The results of this part of the task are conceptualized as verbal shortterm memory abilities. After 30 minutes, however, these words, mixed with other foreign affective words, are displayed again and the respondent must recognize them. The results of this part of the task are conceptualized as the results of verbal long-term memory.

c) Executive functions, cognitive control was measured by Go/No Go task, which has been used in cognitive neuroscience to explore control, executive, inhibitory dysfunction (DeLaRosa et al., 2020). There were 12 stimulus words in this task: 4 negative, 4 neutral and 4 positive words, which were randomly displayed on the screen for 0.7 seconds and the participant had to quickly assess whether the displayed word was negative, neutral or positive following the instructions. Each word was repeated 6 times, so the participant had to evaluate a total of 72 words, with or without pressing a key. The results of this task are conceptualized as cognitive control, inhibition of executive functions, supervision functions.

d) N-back task was created to evaluate the simultaneous storage and processing of working memory as well as inhibition, decision making, updating functions (Kreutzer et al., 2018). In this study task, participants were shown mixed words in a mixed order, including 5 negative, 5 neutral, and 5 positive target words, as well as the same number of false affective words. Accordingly, participants had to remember the word they remembered one, two or three words back at certain times and press the appropriate key on the computer keyboard. The results of this task are conceptualized as a function of working memory storage, updating and inhibition. Separate indicators of Working memory Storage for negative, neutral, positive words, as well as Working memory Inhibition for false affective words were calculated for this test.

The reliability indicators of depression and core affect variables in this study are presented at the beginning of the results section.

\section{Data analysis}

JASP 0.14.1 (JASP Team, 2020), G*Power (Faul et al., 2009) were used for data analysis calculating for all variables: the means, standard deviations, internal consistency, Spearman correlation coefficients. The accordance of all variables to the normal distribution was determined using excess and asymmetry criteria and the Shapiro-Wilk test. The predefined level of statistical significance was $p<.05$. To transform non-normal dependent variable - depression sum score - Box Cox transformation was made (Box \& Cox, 1964). 
We performed a power analysis, determining that the smallest effect of interest for the regression model is $d=.15$, based on previous studies (Rock et al., 2014). Given that the regression model includes 26 independent variables and $\alpha$ error probability $=.05$, the minimum sample size should be at least $n=225$, which is larger in this study.

\section{Results}

The internal consistency for the depression scale was $\alpha=.94$, and, for the SCAS scales, valence $\alpha=.89$ and activation $\alpha=.83$ (see Table 1 for descriptive statistics of all study variables). The test-retest reliability test was performed only for the Finger tapping test in a sample $\mathrm{N}=42$ and the results indicate strong correlation between repeated measurements (right hand $r=.87$ and left hand $r=.90$ ). As can be seen in the Table 1 , the internal consistency indices for cognitive tasks range from $\alpha=.58$ to .80 , indicating that the task items correspond mostly from satisfactory to good reliability. Internal consistency indicators were calculated only for the target stimulus scales, as the false answers rates have too little variation to reliably calculate the levels of reliability. To answer the research question, a correlation analysis of all variables was performed (see Table 3 in the Appendix for a full correlation matrix) to determine the degree of independence of the variables and their compliance with the requirements of the regression equation. Looking at the interrelationships of the variables, it can be concluded that core affect valence and activation are positively correlated positively $\left(r_{\mathrm{s}}=.56\right)$, but it is known from previous studies (Västfjäll et al., 2002) that although these dimensions are related, they are conceptualized as two different constructs of core affect.

The inter-correlations indicate that the psychomotor speed indicators for the right and left hand are closely correlated $\left(r_{\mathrm{s}}=.76 p<.001\right)$, thus their total calculated variable was used in further calculations. Although the index of positive words of executive functions, cognitive control correlates quite closely with the index of negative words $\left(r_{s}=.59 p<.001\right)$, not exceeding the conventional threshold of $r_{\mathrm{s}}=.60$, their separate indicators were used in further calculations. In turn, the working memory storage indicators for negative, neutral and positive words correlate closely with each other, above $r_{s}=.70$, thus in their further calculations their total indicator - working memory storage variable was used. Similarly, indicators of working memory false negative, neutral and positive words form a relationship of more than 0.70 , so they were combined into one indicator - working memory affective false words, which can be conceptualized as a working memory inhibition indicator. 
Table 1. Descriptive statistics for the study variables

\begin{tabular}{|c|c|c|c|c|c|c|c|}
\hline Variable & Min & $\operatorname{Max}$ & $M$ & $S D$ & $M d n$ & $S$-W test & $\alpha$ \\
\hline Depression symptom sum score & 0.00 & 27.00 & 8.88 & 6.85 & 7.00 & $.92 * * *$ & .94 \\
\hline Valence & 1.00 & 9.00 & 6.07 & 1.67 & 6.33 & $.97 * * *$ & .89 \\
\hline Activation & 1.67 & 9.00 & 5.39 & 1.71 & 5.33 & $.98 * * *$ & .83 \\
\hline Psychomotor speed, right hand & 21.00 & 81.67 & 56.40 & 9.90 & 57.33 & $.99 * *$ & \\
\hline Psychomotor speed, left hand & 18.67 & 87.00 & 51.48 & 9.58 & 52.00 & .99 & \\
\hline $\begin{array}{l}\text { Shotterm memory, negative } \\
\text { words }\end{array}$ & 0.00 & 5.00 & 4.23 & 1.03 & 5.00 & $.75^{* * *}$ & .64 \\
\hline Shortterm memory, neutral words & 1.00 & 5.00 & 4.40 & 0.82 & 5.00 & $.73 * * *$ & .61 \\
\hline $\begin{array}{l}\text { Shortterm memory, positive } \\
\text { words }\end{array}$ & 0.00 & 5.00 & 3.85 & 1.12 & 4.00 & $.85 * * *$ & .70 \\
\hline Shortterm memory, false words & 0.00 & 10.00 & 1.25 & 1.63 & 1.00 & $.75^{* * *}$ & \\
\hline $\begin{array}{l}\text { Longterm memory, negative } \\
\text { words }\end{array}$ & 0.00 & 5.00 & 3.41 & 1.40 & 4.00 & $.88 * * *$ & .62 \\
\hline Longterm memory, neutral words & 0.00 & 5.00 & 3.86 & 1.07 & 4.00 & $.86 * * *$ & .59 \\
\hline Longterm memory, positive words & 0.00 & 5.00 & 3.64 & 1.16 & 4.00 & $.89 * * *$ & .60 \\
\hline Longterm memory, false words & 0.00 & 12.00 & 1.99 & 2.15 & 1.50 & $.81 * * *$ & \\
\hline $\begin{array}{l}\text { Executive functions, Cognitive } \\
\text { control, Negative words }\end{array}$ & 0.00 & 16.00 & 12.48 & 3.06 & 13.00 & $.88^{* * *}$ & .61 \\
\hline $\begin{array}{l}\text { Executive functions, Cognitive } \\
\text { control, Neutral words }\end{array}$ & 0.00 & 16.00 & 6.46 & 3.05 & 7.00 & $.99 * *$ & .58 \\
\hline $\begin{array}{l}\text { Executive functions, Cognitive } \\
\text { control, Positive words }\end{array}$ & 2.00 & 16.00 & 9.64 & 3.43 & 10.00 & $.97 * * *$ & .61 \\
\hline $\begin{array}{l}\text { Working memory, Storage, } \\
\text { Negative words }\end{array}$ & 0.00 & 6.00 & 3.13 & 1.80 & 3.00 & $.91 * * *$ & .72 \\
\hline $\begin{array}{l}\text { Working memory, Storage, } \\
\text { Neutral words }\end{array}$ & 0.00 & 4.00 & 2.14 & 1.11 & 2.00 & $.90 * * *$ & .60 \\
\hline $\begin{array}{l}\text { Working memory, Storage, } \\
\text { Positive words }\end{array}$ & 0.00 & 6.00 & 3.15 & 2.07 & 4.00 & $.89 * * *$ & .80 \\
\hline $\begin{array}{l}\text { Working memory, Inhibition, } \\
\text { False negative words }\end{array}$ & 0.00 & 6.00 & 2.75 & 1.77 & 2.00 & $.91 * * *$ & \\
\hline $\begin{array}{l}\text { Working memory, Inhibition, } \\
\text { False neutral words }\end{array}$ & 0.00 & 4.00 & 1.81 & 1.09 & 2.00 & $.90 * * *$ & \\
\hline $\begin{array}{l}\text { Working memory, Inhibition, } \\
\text { False positive words }\end{array}$ & 0.00 & 6.00 & 2.71 & 2.07 & 2.00 & $.88 * * *$ & \\
\hline Age & 20.00 & 59.00 & 37.47 & 11.13 & 37.00 & $.95 * * *$ & \\
\hline Education & 8.00 & 29.00 & 14.62 & 3.66 & 14.00 & $.91 * * *$ & \\
\hline
\end{tabular}

$* p<.05, * * p<.01, * * * p<.001$.

Note: Test-retest reliability was calculated for psychomotor speed indicators. 
From the point of view of convergent validity, short-term and longterm memory scores are weakly and moderately $\left(r_{s}=.13 ; .46\right)$ correlated with long-term memory scores, cognitive control positive and negative word scores $\left(r_{s}=.23 ; .27\right)$, and weakly with working memory storage scores $\left(r_{s}=.12 ; .16\right)$ and negatively with working memory false words $\left(r_{s}=-.12-.14\right)$. Interestingly, the cognitive control negative word index correlates with the working memory storage index $\left(r_{s}=.20 ; .26\right)$, but the cognitive control positive words correlate only with the working memory storage negative word index $\left(r_{s}=.15\right)$. In general, these correlations indicate that test scores form a logical relationship with each other and can serve as a partial basis for the validity of these tasks.

As shown in Table 3, the depression index is negatively correlated with the core affect valences $\left(r_{s}=0.47\right)$ and activation $\left(r_{s}=-.32\right)$. The depression index consists of a negative relationship with the short-term memory neutral words index $\left(r_{s}=-.12\right)$, a positive relationship with the working memory neutral words index $\left(r_{s}=.24\right)$ and a negative relationship with the working memory false neutral words index $\left(r_{s}=-.23\right)$.

To analyze the explained variation with core affect dimensions, cognitive functions, hierarchical regression analysis was performed with the depression sum score as dependent variable. In the first and the second step of analysis, core affect valence and activation were inserted in regression equation to control for other next cognitive functions variables. Cognitive functions variables were entered in stepwise order because there is a lack of clear assumptions about the sequence of cognitive functions and rather their parallel interactions can be accepted.

The hierarchical multiple regression revealed that at step one core affect valence contributed significantly to the regression model, $\mathrm{F}(1,274)=34.51,67, p<.001$ and accounted for $22 \%$ of the variation in depression. In step two were added Core affect Activation, which did not make a statistically significant contribution, but the explained variance increased to $24 \%$. Each of next steps made significant changes in $R^{2}{ }_{\text {adj }}$ respectively in step three to $27 \%$ Core Affect and Working memory Inhibition for affective false words, in step four to $29 \%$ Core Affect, Working memory Storage, Working memory Inhibition for affective false words. In last, fifth step core affect, Working memory Storage, Working memory Inhibition for false affective words, and Executive functions cognitive control for positive words significantly explained the depression sum score $F(5,270)=11.89, p<.001$, and the total variation was $R_{\text {adj }}^{2}=.31$ (see Table 2). In each of the steps, core affect activation was not statistically significant variable. 
Table 2. Hierarchical regression for core affect, cognitive functions predicting depression

\begin{tabular}{|c|c|c|c|c|c|c|c|c|}
\hline & & $B$ & CI 95\% & SE & $\beta$ & $R_{\text {adj }}^{2}$ & $F$ & $\mathbf{t}$ \\
\hline 1 & (Constant) & 21.12 & $16.92 ; 25.32$ & 2.12 & & \multirow{2}{*}{.22} & \multirow{2}{*}{$34.51 * * *$} & $9.96^{* * * *}$ \\
\hline & Core affect, Valence & -2.00 & $-2.68 ;-1.33$ & 0.34 & -.48 & & & $-5.88 * * *$ \\
\hline \multirow[t]{3}{*}{2} & (Constant) & 22.94 & $18.34 ; 27.55$ & 2.33 & & \multirow{3}{*}{.24} & \multirow{3}{*}{$19.27 * * *$} & $9.87 * * *$ \\
\hline & Core affect, Valence & -1.68 & $-2.44 ;-0.92$ & 0.38 & -.40 & & & $-4.40 * * *$ \\
\hline & Core affect, Activation & -0.71 & $-1.47 ; 0.06$ & 0.39 & -.17 & & & -1.83 \\
\hline \multirow[t]{4}{*}{3} & (Constant) & 19.26 & $13.86 ; 24.66$ & 2.73 & & \multirow{4}{*}{.27} & \multirow{4}{*}{$15.39 * * *$} & $7.06 * * *$ \\
\hline & Core affect, Valence & -1.60 & $-2.34 ;-0.85$ & 0.38 & -.38 & & & $-4.25 * * *$ \\
\hline & Core affect, Activation & -0.61 & $-1.37 ; 0.14$ & 0.38 & -.14 & & & -1.61 \\
\hline & $\begin{array}{l}\text { WM, Inhibition, } \\
\text { Affective false words }\end{array}$ & 0.35 & $0.07 ; 0.63$ & 0.14 & .20 & & & $2.45^{*}$ \\
\hline \multirow[t]{5}{*}{4} & (Constant) & 20.36 & $14.94 ; 25.76$ & 2.74 & & \multirow{5}{*}{.29} & \multirow{5}{*}{$13.03 * * *$} & $7.44 * * *$ \\
\hline & Core affect, Valence & -1.55 & $-2.29 ;-0.82$ & 0.37 & -.37 & & & $-4.19 * * *$ \\
\hline & Core affect, Activation & -0.48 & $-1.23 ; 0.27$ & 0.38 & -.11 & & & -1.26 \\
\hline & WM, Storage & 0.39 & $0.11 ; 0.67$ & 0.14 & .22 & & & $2.75 * *$ \\
\hline & $\begin{array}{l}\text { WM, Inhibition, } \\
\text { Affective false words }\end{array}$ & -0.29 & $-0.55 ;-0.02$ & 0.13 & -.17 & & & $-2.13 *$ \\
\hline \multirow[t]{6}{*}{5} & (Constant) & 23.12 & $17.29 ; 28.95$ & 2.94 & & \multirow{6}{*}{.31} & \multirow{6}{*}{$11.89 * * *$} & $7.86 * * *$ \\
\hline & Core affect, Valence & -1.33 & $-2.07 ;-0.58$ & 0.38 & -.32 & & & $-3.53 * * *$ \\
\hline & Core affect, Activation & -0.54 & $-1.28 ; 0.21$ & 0.37 & -.13 & & & -1.43 \\
\hline & WM, Storage & 0.42 & $0.15 ; 0.69$ & 0.14 & .24 & & & $3.03 * *$ \\
\hline & $\begin{array}{l}\text { WM, Inhibition, } \\
\text { Affective false words }\end{array}$ & -0.33 & $-0.59 ;-0.67$ & 0.13 & -.20 & & & $-2.48^{*}$ \\
\hline & $\begin{array}{l}\text { EF, Cognitive control, } \\
\text { Positive words }\end{array}$ & -0.39 & $-0.73 ;-0.06$ & 0.17 & -.18 & & & $-2.31 *$ \\
\hline
\end{tabular}

$* p<.05, * * p<.01, * * * p<.001$.

Note: $\beta$-regression coefficient (unstandardized); CI 95\%—confidence interval; WM working memory; EF - executive functions.

A significant part of the variation is explained in first step of hierarchical regression by the Core affect valence factor $(\beta=-.48)$ and in step two with Activation $(\beta=-.17)$ explained $24 \%$. But Activation is not statistically significant most likely because one is closely correlated with Valence. Other cognitive functions - Working memory Storage $(\beta=.24)$, WM, Inhibition for affective false words $(\beta=-.20)$ and Executive functions 
Cognitive control for positive words $(\beta=-.18)$ explained additional $9 \%$ of variation. Neither age, education, nor Short-term memory, Long-term memory and Executive functions Cognitive control for neutral and negative words, and Psychomotor speed made a statistically significant contribution to the regression model.

The Durbin-Watson test, which helps to determine whether the residuals of an equation are independent, led to the conclusion that there were statistically significant positive autocorrelations between residuals of 1,47. This indicates the probability of errors in the explained variation and the inter-correlations of the residuals (Montgomery et al., 2012). The collinearity conditions correspond to the accepted ones with VIF (variance inflation factor) $1.02-1.21$ and tolerance $0.82-0.97$.

The following covariates were included in the model but removed in the stepwise regression: Short term memory for Negative, Positive, Neutral words, False words; Long term memory for Negative, Positive, Neutral words, False words; Executive functions Cognitive control for neutral, negative words; Psychomotor speed; Age; Education.

\section{Discussion}

To find out how depressive symptoms in healthy sample are related to cognitive functions controlling the core affect, we performed hierarchical regression model analysis. Regression analysis allowed us to observe that depression symptoms are best explained mostly by the core affect valence factor or current mood state and after controlling both of core affect dimensions ( $24 \%$ variance) the depression is explained by working memory inhibition for affective words, working memory storage factor, and executive functions cognitive control for positive words (31\% of total model variance). Neither age, education, nor short-term, long-term memory factors made a significant contribution.

Interestingly that we observed although the number of errors in remembering false affective words is elevated at hightened levels of depressive symptoms, the working memory storage index is also positive, which may suggest that working memory capacity may not be impaired in the presence of elevated symptoms of mood disorders. However, from the cognitive functions the most significant proportion is explained by the factors of working memory. Previous studies also show data, suggesting that both normative healthy individuals and individuals with depressive disorders show deficiencies in various work memory and executive functions, despite the valence of stimulus words, and these relationships are not robust (Zhang et al., 2018) and findings on cognitive biases in depression and anxiety are not consistent (Eysenck \& Fajkowska, 2018). 
Thus, we can observe in this sample, that after controlling valence of current state of mood in moment of doing cognitive tasks, the most related and thus probably impaired functions due to highttened depression are working memories inhibition function for affective verbal intrusions, and executive functions cognitive control for positive verbal information, however, working memory capacity may be relatively intact. This suggests that we can observe an input-gate mechanism that may remain ineffective with increased depressive symptoms and more frequent errors, deviations from optimal performance (Gajewski et al., 2018; Kessler \& Oberauer, 2015). Overall, this is the first study to examine the relationship between depression and cognitive function by controlling the current mood state or core affect dimensions. As is known, individuals with depressive disorders have significant fluctuations in current mood, affect levels (Schoevers et al., 2020), and thus retrospective assessment of symptoms may not include all relevant information. The results suggest that a significant level of depressive symptoms is explained by current mood levels and only then could cognitive impairment be considered. The results obtained in this study may suggest that the effect sizes obtained in previous studies, when measuring the association of cognitive function with depression, may be much smaller if the current mood is controlled. An additional novelty in this study is that depression was measured with a tripartite model instrument DASS-42 that better differentiates depressive symptoms from anxiety and distress symptoms (Lovibond \& Lovibond, 1995).

The disadvantage of this study is the overall relatively small sample, as well as the sample of normatively healthy individuals, which does not allow to conclude about the true relationships of cognitive function with depressive symptoms. In addition, only age, level of education, but none of the other dozens of factors that affect cognitive function, such as previous night's sleep, quality, computer experience, current illness, medications, and food, were monitored in this study.

\section{Conclusions}

The results of the study lead to the conclusion that the symptoms of depression in normatively healthy individuals after controlling current affective state (core affect) are significantly predicted by deficits of working memory inhibition and executive functions cognitive control factors. This point to significant interrelationships and the important role of inhibition, cognitive control, working memory storage functions in these mutual relations between current affective state, possible affective disturbances. These relationships need to be investigated in the future at the level of individual symptoms as well as in samples of clinical disorders. 


\section{References}

Bora, E., Harrison, B. J., Yücel, M., \& Pantelis, C. (2013). Cognitive impairment in euthymic major depressive disorder: A meta-analysis. Psychological Medicine, 43(10), 2017-2026. https://doi.org/10.1017/S0033291712002085

Box, G. E. P., \& Cox, D. R. (1964). An Analysis of Transformations. Journal of the Royal Statistical Society: Series B (Methodological), 26(2), 211-243. https://doi. org/10.1111/j.2517-6161.1964.tb00553.x

Chepenik, L. G., Cornew, L. A., \& Farah, M. J. (2007). The influence of sad mood on cognition. Emotion, 7(4), 802-811. https://doi.org/10.1037/1528-3542.7.4.802

Clark, L. A., \& Watson, D. (1991). Tripartite model of anxiety and depression: Psychometric evidence and taxonomic implications. Journal of Abnormal Psychology, 100(3), 316-336. https://doi.org/10.1037/0021-843X.100.3.316

Conway, C. C., Zinbarg, R. E., Mineka, S., \& Craske, M. G. (2017). Core Dimensions of Anxiety and Depression Change Independently During Adolescence. Journal of Abnormal Psychology, 126(2), 160-172. https://doi.org/10.1037/abn0000222

Cummins, R. A. (2014). Core Affect. In A. C. Michalos (Ed.), Encyclopedia of Quality of Life and Well-Being Research (pp. 1298-1302). Springer Netherlands. https://doi. org/10.1007/978-94-007-0753-5_581

DeLaRosa, B. L., Spence, J. S., Motes, M. A., To, W., Vanneste, S., Kraut, M. A., \& Hart, J. (2020). Identification of selection and inhibition components in a Go/NoGo task from EEG spectra using a machine learning classifier. Brain and Behavior, 10(12), e01902. https://doi.org/10.1002/brb3.1902

Ekkekakis, P., \& Petruzzello, S. J. (2002). Analysis of the affect measurement conundrum in exercise psychology: IV. A conceptual case for the affect circumplex. Psychology of Sport and Exercise, 3(1), 35-63. https://doi.org/10.1016/S1469-0292(01)00028-0

Erickson, K., Drevets, W. C., Clark, L., Cannon, D. M., Bain, E. E., Zarate, C. A., Charney, D. S., \& Sahakian, B. J. (2005). Mood-Congruent Bias in Affective Go/No-Go Performance of Unmedicated Patients With Major Depressive Disorder. American Journal of Psychiatry, 162(11), 2171-2173. https://doi.org/10.1176/appi.ajp.162.11.2171

Eysenck, M. W., \& Fajkowska, M. (2018). Anxiety and depression: Toward overlapping and distinctive features. Cognition and Emotion, 32(7), 1391-1400. https://doi.org/10.1 080/02699931.2017.1330255

Faul, F., Erdfelder, E., Buchner, A., \& Lang, A.-G. (2009). Statistical power analyses using $\mathrm{G}^{*}$ Power 3.1: Tests for correlation and regression analyses. Behavior Research Methods, 41(4), 1149-1160. https://doi.org/10.3758/BRM.41.4.1149

Fried, E. I. (2015). Problematic assumptions have slowed down depression research: Why symptoms, not syndromes are the way forward. Frontiers in Psychology, 6. https:// doi.org/10.3389/fpsyg.2015.00309

Fried, E. I. (2017). The 52 symptoms of major depression: Lack of content overlap among seven common depression scales. Journal of Affective Disorders, 208, 191-197. https://doi.org/10.1016/j.jad.2016.10.019

Fried, E. I. (2019). 2019-04 Depression is a problematic phenotype. https://doi.org/ 10.17605/OSF.IO/QDKPW

Gajewski, P. D., Hanisch, E., Falkenstein, M., Thönes, S., \& Wascher, E. (2018). What Does the n-Back Task Measure as We Get Older? Relations Between Working-Memory Measures and Other Cognitive Functions Across the Lifespan. Frontiers in Psychology, 9. https://doi.org/10.3389/fpsyg.2018.02208 
Halvorsen, M., Waterloo, K., Sundet, K., Eisemann, M., \& Wang, C. E. A. (2011). Verbal learning and memory in depression: A 9-year follow-up study. Psychiatry Research, 188(3), 350-354. https://doi.org/10.1016/j.psychres.2011.02.022

Huang, C. L.-C. (2010). The Value of Patient-administered Depression Rating Scale in Detecting Cognitive Deficits in Depressed Patients. Journal of Clinical Medicine Research. https://doi.org/10.4021/jocmr2010.02.224w

Ji, Y., Li, W., Liu, B., Liu, J., Ju, Y., Wang, M., Chen, Y., Li, L., Ji, Y., Li, W., Liu, B., Liu, J., Ju, Y., Wang, M., Chen, Y., \& Li, L. (2020). Clinical characteristics of cognitive deficits in major depressive disorder: A 6-month prospective study. Archives of Clinical Psychiatry (São Paulo), 47(4), 101-105. https://doi.org/10.1590/0101-60830000000241

Kessler, Y., \& Oberauer, K. (2015). Forward scanning in verbal working memory updating. Psychonomic Bulletin \& Review, 22(6), 1770-1776. https://doi.org/10.3758/ s13423-015-0853-0

Knight, M. J., Lyrtzis, E., \& Baune, B. T. (2020). The association of cognitive deficits with mental and physical Quality of Life in Major Depressive Disorder. Comprehensive Psychiatry, 97, 152147. https://doi.org/10.1016/j.comppsych.2019.152147

Kreutzer, J.S., DeLuca, J., \& Caplan,B.(Eds.). (2018). Encyclopedia ofClinical Neuropsychology. Springer International Publishing. https://doi.org/10.1007/978-3-319-57111-9

Liberg, B., Adler, M., Jonsson, T., Landén, M., Rahm, C., Wahlund, L.-O., KristoffersenWiberg, M., \& Wahlund, B. (2013). The neural correlates of self-paced finger tapping in bipolar depression with motor retardation. Acta Neuropsychiatrica, 25(1), 43-51. https://doi.org/10.1111/j.1601-5215.2012.00659.x

Lovibond, P. F., \& Lovibond, S. H. (1995). The structure of negative emotional states: Comparison of the Depression Anxiety Stress Scales (DASS) with the Beck Depression and Anxiety Inventories. Behaviour Research and Therapy, 33(3), 335-343. https://doi.org/ 10.1016/0005-7967(94)00075-U

Montgomery, D. C., Peck, E. A., \& Vining, G. G. (2012). Introduction to linear regression analysis $\left(5^{\text {th }}\right.$ ed). Wiley.

Nikolin, S., Tan, Y. Y., Schwaab, A., Moffa, A., Loo, C. K., \& Martin, D. (2021). An investigation of working memory deficits in depression using the n-back task: A systematic review and meta-analysis. Journal of Affective Disorders, 284, 1-8. https://doi.org/ 10.1016/j.jad.2021.01.084

Rock, P. L., Roiser, J. P., Riedel, W. J., \& Blackwell, A. D. (2014). Cognitive impairment in depression: A systematic review and meta-analysis. Psychological Medicine, 44(10), 2029-2040. Scopus. https://doi.org/10.1017/S0033291713002535

Russell, J. A. (2003). Core affect and the psychological construction of emotion. Psychological Review, 110(1), 145-172. https://doi.org/10.1037/0033-295X.110.1.145

Schoevers, R. A., van Borkulo, C. D., Lamers, F., Servaas, M. N., Bastiaansen, J. A., Beekman, A. T. F., van Hemert, A. M., Smit, J. H., Penninx, B. W. J. H., \& Riese, H. (2020). Affect fluctuations examined with ecological momentary assessment in patients with current or remitted depression and anxiety disorders. Psychological Medicine, 1-10. https://doi.org/10.1017/S0033291720000689

Schraedley, P. K., Turner, R. J., \& Gotlib, I. H. (2002). Stability of Retrospective Reports in Depression: Traumatic Events, Past Depressive Episodes, and Parental Psychopathology. Journal of Health and Social Behavior, 43(3), 307. https://doi.org/10.2307/3090206

Scult, M. A., Paulli, A. R., Mazure, E. S., Moffitt, T. E., Hariri, A. R., \& Strauman, T. J. (2017). The association between cognitive function and subsequent depression: 
A systematic review and meta-analysis. Psychological Medicine, 47(1), 1-17. https://doi. org/10.1017/S0033291716002075

Semkovska, M., Quinlivan, L., O'Grady, T., Johnson, R., Collins, A., O'Connor, J., Knittle, H., Ahern, E., \& Gload, T. (2019). Cognitive function following a major depressive episode: A systematic review and meta-analysis. The Lancet Psychiatry, $O(0)$. https://doi. org/10.1016/S2215-0366(19)30291-3

Strauss, E., Sherman, E. M. S., \& Spreen, O. (2006). A Compendium of Neuropsychological Tests: Administration, Norms, and Commentary. Oxford University Press.

Vanags, E., \& Raščevska, M. (2017). Depression, Anxiety and Stress Scale (DASS-42) Reliability and Validity. Baltic Journal of Psychology, 2017, 13. https://doi.org/10.22364/ bjp.18.01-02

Västfjäll, D., Friman, M., Gärling, T., \& Kleiner, M. (2002). The measurement of core affect: A Swedish self-report measure derived from the affect circumplex. Scandinavian Journal of Psychology, 43(1), 19-31. https://doi.org/10.1111/1467-9450.00265

Zhang, D., Xie, H., He, Z., Wei, Z., \& Gu, R. (2018). Impaired Working Memory Updating for Emotional Stimuli in Depressed Patients. Frontiers in Behavioral Neuroscience, 12. https://doi.org/10.3389/fnbeh.2018.00065

Zuckerman, H., Pan, Z., Park, C., Brietzke, E., Musial, N., Shariq, A. S., Iacobucci, M., Yim, S. J., Lui, L. M. W., Rong, C., \& McIntyre, R. S. (2018). Recognition and Treatment of Cognitive Dysfunction in Major Depressive Disorder. Frontiers in Psychiatry, 9. https:// doi.org/10.3389/fpsyt.2018.00655 


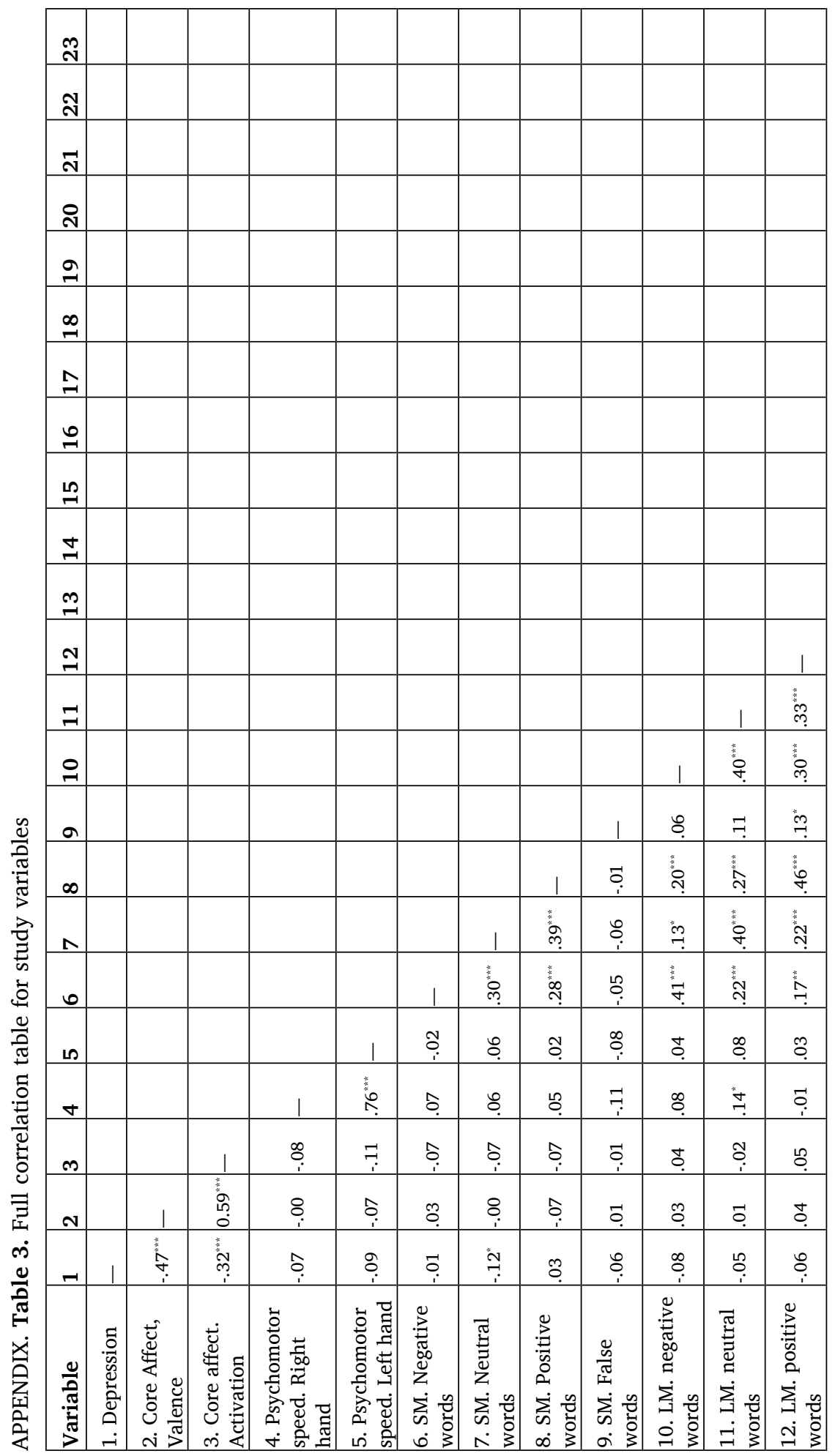




\begin{tabular}{|c|c|c|c|c|c|c|c|c|c|c|c|}
\hline & & & & & & & & & & 1 & $\begin{array}{l}0 \\
0 \\
0 \\
1\end{array}$ \\
\hline & & & & & & & & & 1 & 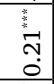 & $\begin{array}{l}2 \\
0 \\
0 \\
1\end{array}$ \\
\hline & & & & & & & & 1 & $\stackrel{n}{\stackrel{0}{~}}$ & \begin{tabular}{l}
$\mathbf{1}$ \\
\multirow{3}{*}{} \\
0
\end{tabular} & $\begin{array}{l}0 \\
0 \\
\dot{1} \\
\end{array}$ \\
\hline & & & & & & & 1 & 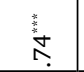 & $\stackrel{1}{\infty}$ & 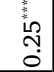 & $\begin{array}{l}8 \\
0 \\
0 \\
1\end{array}$ \\
\hline & & & & & & | & ọ & $\stackrel{\sim}{\dddot{i}}$ & $\stackrel{\circ}{?}$ & $\begin{array}{l}\text { N̦ } \\
\stackrel{1}{1}\end{array}$ & $\begin{array}{l}\hat{0} \\
0 \\
0\end{array}$ \\
\hline & & & & & 1 & $\stackrel{*}{\star}$ & $\underset{i}{+}$ & $\stackrel{\text { : }}{\stackrel{9}{\circ}}$ & $\stackrel{\text { L }}{\circ}$ & 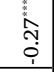 & $\begin{array}{l}0 \\
0 \\
0\end{array}$ \\
\hline & & & & | & 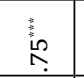 & $\begin{array}{l}1 \\
\infty \\
\end{array}$ & $\begin{array}{l}1 \\
\infty \\
\rightarrow \\
i\end{array}$ & $\begin{array}{l}\text {. } \\
\text { 구 } \\
\end{array}$ & $\underset{\text { o }}{\text { o }}$ & 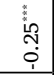 & $\begin{array}{l}8 \\
0 \\
0\end{array}$ \\
\hline & & & 1 & 藏 & $F$ & 8 & $\stackrel{m}{\sim}$ & $\Rightarrow$ & ọ & ָे & $\stackrel{\sim}{\stackrel{2}{0}}$ \\
\hline & & 1 & $\stackrel{+}{+}$ & $\stackrel{\infty}{\circ}$ & 농 & 농 & $\stackrel{\infty}{0}$ & $\stackrel{m}{\infty}$ & $\underset{i}{N}$ & $\begin{array}{l}\text { in } \\
\text { ? } \\
0\end{array}$ & $\begin{array}{l}\text { ⿵人 } \\
0 \\
\dot{1}\end{array}$ \\
\hline & 1 & 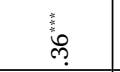 & $\begin{array}{l}\text {. } \\
\text { مे } \\
\end{array}$ & เి & ڤั. & คิ & 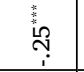 & 국 & $\stackrel{3}{7}$ & 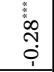 & $\overrightarrow{7}$ \\
\hline 1 & ì & $\sigma_{i}$ & $\stackrel{\infty}{\stackrel{\infty}{7}}$ & 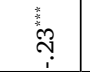 & 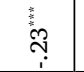 & $\stackrel{\infty}{\infty}$ & ฟุ & 恙 & b & $\begin{array}{l}0 \\
0 \\
0 \\
0\end{array}$ & $\begin{array}{l}m \\
\stackrel{0}{0} \\
\stackrel{0}{1}\end{array}$ \\
\hline$\stackrel{0}{\stackrel{1}{r}}$ & $\stackrel{\text { ta }}{\circ}$ & $\stackrel{0}{\circ}$ & 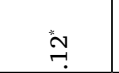 & 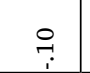 & ơ & $\underset{i}{+}$ & $\stackrel{ }{\circ}$ & ชิ & ț & $\begin{array}{l}0 \\
\stackrel{0}{0} \\
0\end{array}$ & $\begin{array}{l}\tilde{D} \\
\stackrel{0}{0} \\
\dot{d}\end{array}$ \\
\hline ชิ & 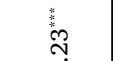 & $\stackrel{\circ}{\circ}$ & $\stackrel{1}{\sim}$ & $\sigma$ & бo & 8 & 8 & ชิ & 8 & $\begin{array}{l}8 \\
0 \\
0\end{array}$ & 8 \\
\hline 우 & $\stackrel{1}{\circ}$ & Hั & $\stackrel{m}{\rightarrow}$ & to & to & \%ి. & $\underset{i}{+}$ & ర్t & $\underset{i}{+}$ & $\begin{array}{l}0 \\
0 \\
0 \\
0\end{array}$ & $\begin{array}{l}0 \\
0 \\
0\end{array}$ \\
\hline ip & $\stackrel{\square}{i}$ & $\overrightarrow{0}$ & $\stackrel{\infty}{0}$ & $\stackrel{\infty}{\infty}$ & $\begin{array}{l}3 \\
\stackrel{3}{0} \\
7\end{array}$ & $\stackrel{*}{7}$ & ?. & 축 & . & 8 & $\begin{array}{l}\hat{0} \\
\stackrel{0}{0}\end{array}$ \\
\hline \%ి & $\stackrel{\text { ॥. }}{\text { ஸे }}$ & o. & $\stackrel{+}{\square}$ & ô & $\stackrel{*}{\sim}$ & $\stackrel{?}{?}$ & ô & $F_{i}$ & $\stackrel{*}{7}$ & $\begin{array}{l}1 \\
0 \\
1 \\
\end{array}$ & $\begin{array}{l}\text { ô } \\
0 \\
\\
\end{array}$ \\
\hline $\overrightarrow{7}_{i}$ & 今̣ & $\stackrel{\text { o }}{0}$ & $\stackrel{+}{\square}$ & \begin{tabular}{l}
0 \\
\hdashline
\end{tabular} & $\stackrel{*}{*}$ & $\begin{array}{l}0 \\
0\end{array}$ & $\stackrel{\text { th }}{7}$ & $\stackrel{m}{\stackrel{7}{7}}$ & 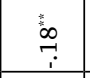 & $\begin{array}{l}+ \\
+ \\
0 \\
\end{array}$ & $\begin{array}{l}\stackrel{2}{0} \\
0 \\
0\end{array}$ \\
\hline$\stackrel{\infty}{\stackrel{\infty}{i}}$ & $\stackrel{0}{\circ}$ & $\stackrel{0}{0}$ & ọ. & 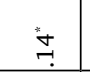 & $\stackrel{m}{\cdots}$ & oे & $\stackrel{*}{\stackrel{*}{*}}$ & $\stackrel{*}{\stackrel{*}{7}}$ & $\vec{F}$ & $\begin{array}{l}3 \\
0 \\
0 \\
0\end{array}$ & $\begin{array}{l}\infty \\
0 \\
0\end{array}$ \\
\hline $\begin{array}{l}0 \\
7 \\
i\end{array}$ & $\stackrel{\leftrightarrow}{\text { ॥. }}$ & $\stackrel{\infty}{\circ}$ & ثุ & $\stackrel{+}{\stackrel{\Delta}{~}}$ & ث̣ & సุ & $\stackrel{\leftrightarrow}{i}$ & \%) & ণิ ฺุ & $\begin{array}{l}0 \\
0 \\
1 \\
1\end{array}$ & $\hat{o}$ \\
\hline$\stackrel{0}{7}$ & 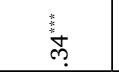 & 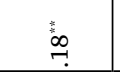 & ث̣ & ث̣ & 羙 & 离 & 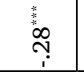 & 站 & $\stackrel{1}{\stackrel{1}{1}}$ & ָิ & $\stackrel{m}{\rightarrow}$ \\
\hline ọ & $\stackrel{*}{\stackrel{2}{7}}$ & 8 & $\hat{\text { so }}$ & $\overrightarrow{7}$ & $\stackrel{*}{\sim}$ & $\vec{i}$ & o. & $\exists$ & $\stackrel{\circ}{\because}$ & 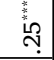 & 8 \\
\hline ơ & or & ๓ి & ¿̊. & to & $\stackrel{?}{?}$ & to & tọ & o. & 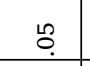 & $\hat{o}$ & ô. \\
\hline$\stackrel{2}{\circ}$ & ồ & $\underset{i}{t}$ & 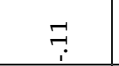 & ọ & 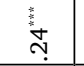 & $\stackrel{?}{?}$ & $\stackrel{0}{?}$ & 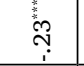 & ๆ & $\begin{array}{l}\infty \\
\stackrel{0}{i}\end{array}$ & oे \\
\hline 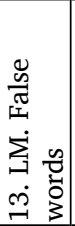 & 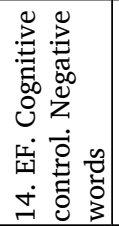 & 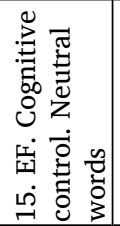 & 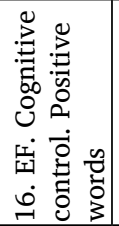 & 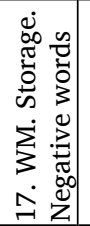 & 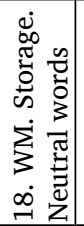 & 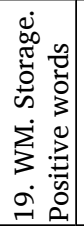 & 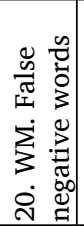 & 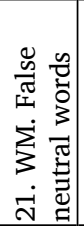 & 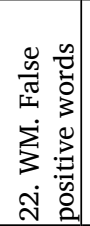 & 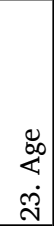 & 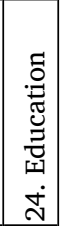 \\
\hline
\end{tabular}

